\title{
AC 2009-1377: CIVIL ENGINEERING COURSES TAUGHT WITH INDIVIDUALIZED STUDENT ASSIGNMENTS
}

Ahmet Zeytinci, University of the District of Columbia

Philip Brach, University of the District of Columbia 


\title{
CIVIL ENGINEERING COURSES TAUGHT WITH INDIVIDUALIZED STUDENT ASSIGNMENTS
}

\begin{abstract}
One of the problems confronting the present day instructor is that of students cheating. While it is reasonably possible to control student interaction on quizzes and exams taken in class, it is not easy to prevent students from doing other assignments collaboratively. While it is important and encouraged that students work together, reinforcing their individual strengths, it is equally important that they do not simply copy each other's work.

Modern technologies available for use in instruction, such as computers, spreadsheets and math software such as MATLAB, have made it possible to individualize assignments for each student. To accomplish this task prior to current technology was extremely time consuming. These modern tools of technology have made it possible to accomplish individualized problem assignments, quizzes and exams with optimum time and effort on the part of instructor.

Examples of individualized (custom made for each student) problems for civil engineering courses such as structural analysis, foundation design, and mechanics of solids will be presented. A generic guide illustrating a technique to assist the instructor in preparing individualized assignments for virtually any course utilizing formulas and relationships is included.

\section{Comparing Data from Different Years}

Objective (quantitative) comparison of student performance in courses from different years presented a challenge. Each course had different students; the common base was the instructor and the course material. The characteristic that changed in the before and after courses was the introduction of individual assignments in the after sections. To attempt to compare student and class performance in this situation, the authors developed an index system to assign a numerical value to individual student performance in a course and an index to quantify the overall performance of all students in the course. It is proffered that the overall index may be used to demonstrate the effectiveness of the new instructional strategy (individual student assignments). The use of these two indices normalizes the fact that each course has different students, with different individual capabilities
\end{abstract}

\section{Capability and Effectiveness Indices}

The Capability Index (CI) is a measure of a student's personal performance as demonstrated by the relationship between the grade point (GP) they achieve in a course and their cumulative grade point average (CGPA) at the same time (CI=GP/CGPA). The cumulative GPA at the end of the course was used as a reasonable quantitative overall measure of a student's demonstrated capability at that point in time and because it is a readily determined value. The CI is strictly an index related to an individual student. If a student is consistently a straight " $\mathrm{A}$ " student or a straight " $C$ " student then his or her CI will be 1.000. However the index will show relative improvement for a student not a straight "A" student or a decline in relative performance for a straight "A" student who fails to maintain straight "A's". 
The Effectiveness Index (EI) is the average of the CI indices for all the students in a course. It is our hypothesis that a significant improvement in the EI may be used as an indicator of success of a new or different instructional strategy initiated to improve student performance. In that the EI is a measure of the average individual relative performance of all the students in a class it is our proposition that it provides an objective measure of the success of a new instructional strategy such as the Individual Student Assignments proffered by this paper.

\section{Qualitative Assessment}

The use of individualized (custom made) assignments for students has also resulted in an improved student environment. In our engineering classes collaboration among students is encouraged but when using traditional assignments (in which all problems are the same) the risk and peer pressure on some students often results in them simply copying each other's work rather than collaborating to understand the solution. The individualized problems minimize student copying while encouraging collaboration. Rather than copying each other's work, students discuss how the problem should be solved because each problem is different, making it virtually impossible to merely copy the solution.

\section{Ancillary Benefits}

The development of individualized problems by the instructor, rather than using problems in a textbook (textbook problems may be individualized as well) may also benefit the students in that they may purchase older editions of the textbook, especially in those courses for which the only difference in later editions is new problem sets. In today's economy this can mean significant savings for the student.

Once the problem format has been developed in EXCEL, new unique individualized problems may be easily generated by the instructor with little effort, thus eliminating the traditional "fraternity" collection of problem sets of former students maintained for use by later students.

Another important advantage is that using this method early in the course eliminates those students who think they could complete the course relying on the effort of their classmates; students with such expectations tend to drop the course.

\section{Individualized Student Problem}

The steps for developing individualized problems may be summarized as:

1- Select a problem, such as the determination of the maximum deflection of a cantilever beam (see sample problem 1).

2- Express the parameters necessary to solve the problem in generic terms.

3- Draw a figure identifying the known and unknown parameters.

4- Using a spreadsheet such as Excel, formulate the relationships (equations) that are necessary to solve for unknown parameters using the known parameters. This information is not given to the students on their assignment sheet.

5- Create an answer sheet using Excel; the instructor will use this spreadsheet to grade the individual student assignments. 
Sample Problem 1: Note each student has his/her own numerical data

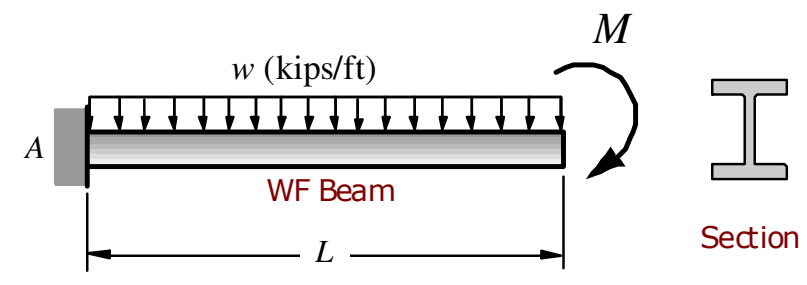

$w$ (kips/ft)

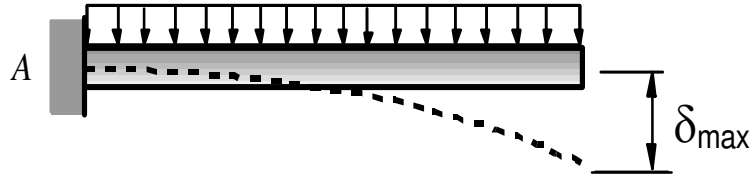

$$
\delta_{\max }=\frac{w L^{4}}{8 E I}+\frac{M L^{2}}{2 E I}
$$

A cantilever beam is loaded as shown. Using the listed data determine the maximum deflection of the beam. Disregard the weight of the beam.

\begin{tabular}{|c|l|c|c|c|c|c|}
\hline & \multirow{2}{*}{ STUDENT } & \multirow{2}{*}{ WF Section } & $L$ & $\boldsymbol{w}$ & $\boldsymbol{M}$ & $\boldsymbol{E}$ \\
\cline { 4 - 7 } & & & $\mathbf{f t}$ & $\mathbf{k} / \mathbf{f t}$ & $\mathbf{k . f t}$ & $\mathbf{x 1 0}^{\mathbf{6}} \mathbf{~ p s i}$ \\
\hline $\boldsymbol{1}$ & Name 1 & $W 24 \times 68$ & 16.0 & 2.00 & 10 & 29.0 \\
\hline $\boldsymbol{2}$ & Name 2 & $W 30 \times 99$ & 18.0 & 2.50 & 28 & 30.0 \\
\hline $\mathbf{3}$ & Ect. & $W 27 \times 84$ & 14.0 & 2.00 & 50 & 29.0 \\
\hline$\ldots$ & & $W 21 \times 62$ & 15.0 & 3.00 & 10 & 29.0 \\
\hline
\end{tabular}

\section{Table 1}

\section{Answers: Sample Problem 1}

The instructor solves the problem in generic terms using an Excel spread sheet, which generates the answers for all problems

\begin{tabular}{|c|c|c|c|c|c|c|c|c|c|}
\hline & $\begin{array}{c}\text { WF } \\
\text { Section }\end{array}$ & $\boldsymbol{L}$ & $\boldsymbol{w}$ & $\boldsymbol{M}$ & $\boldsymbol{E}$ & $\boldsymbol{I}$ & $\boldsymbol{\delta}_{M}$ & $\boldsymbol{\delta}_{w}$ & $\boldsymbol{\delta}_{\max }$ \\
\hline & $\mathrm{ft}$ & $\mathrm{ft}$ & $\mathrm{k} / \mathrm{ft}$ & $\mathrm{k} . \mathrm{ft}$ & $\begin{array}{c}\mathrm{x} 10^{6} \\
\mathrm{psi}\end{array}$ & $\mathrm{in}^{4}$ & in. & in. & in. \\
\hline $\boldsymbol{I}$ & $\boldsymbol{W} 24 \times 68$ & 16.0 & 2.00 & 10.0 & 29.0 & 1830 & 0.0417 & 0.5335 & $\mathbf{0 . 5 7 5 2}$ \\
\hline $\boldsymbol{2}$ & $\boldsymbol{W} 30 \times 99$ & 18.0 & 2.50 & 28.0 & 30.0 & 3990 & 0.7858 & 0.4736 & $\mathbf{1 . 2 5 9 4}$ \\
\hline
\end{tabular}




\begin{tabular}{|l|l|l|l|l|l|l|l|l|l|}
$\mathbf{3}$ & $\boldsymbol{w} 27 \times 84$ & 14.0 & 2.00 & 50.0 & 29.0 & 2850 & 0.9562 & 0.2008 & $\mathbf{1 . 1 5 7 0}$ \\
\hline $\mathbf{4}$ & $\boldsymbol{W} 21 \times 62$ & 15.0 & 3.00 & 10.0 & 29.0 & 1330 & 0.5040 & 0.8505 & $\mathbf{1 . 3 5 4 6}$ \\
\hline
\end{tabular}

\section{Table 2}

The following is a copy of the Excel work sheet showing the cell formulas used to calculate the answers to each individual student problem. Here the following notations are used:

$L: \quad$ Length of the cantilever beam ( $\mathrm{ft}$ )

$w$ : $\quad$ Uniform load acting on the beam (kips/ft)

$M$ : Moment acting at the free end of the cantilever beam (ft-kips)

E: $\quad$ Modulus of elasticity of the beam (psi)

I: $\quad$ Moment of inertia of the beam cross-section (in ${ }^{4}$ )

$\delta_{M}: \quad$ Deflection due to the moment (in.)

$\delta_{w}: \quad$ Deflection due to the uniform load (in.)

$\delta_{\max }:$ Total deflection due to the moment and the uniform load (in.)

\section{Cell Formulas}

\begin{tabular}{|c|c|c|c|c|c|c|c|c|c|c|}
\hline. & A & C & D & $E$ & $\mathrm{~F}$ & G & $\mathrm{H}$ & $\mathrm{K}$ & L & M \\
\hline 6 & & WF Section & $L$ & $w$ & $M$ & $E$ & $I$ & $\delta_{M}$ & $\boldsymbol{\delta}_{w}$ & $\delta_{\max }$ \\
\hline 9 & & $\mathrm{ft}$ & $\mathrm{ft}$ & $\mathrm{k} / \mathrm{ft}$ & k.ft & $\mathrm{x} 10^{6} \mathrm{psi}$ & in $^{4}$ & in. & in. & in. \\
\hline 13 & 1 & $W 24 \times 68$ & 16 & 2 & 10 & 29 & 1830 & $=\left(F 13^{*} 12\right)^{*}\left(D 13^{*} 12\right)^{\wedge} 2 / 2 / G 13 / 1000 / H 13$ & $=E 13^{\star} D 13^{\wedge} 4 / 8 / G 13 / 1000 / H 13^{\star} 12^{\wedge} 3$ & $=K 13+L 13$ \\
\hline 14 & 2 & $W 30 \times 99$ & 18 & 2.5 & 28 & 30 & 3990 & $=F 14^{*}\left(D 14^{*} 12\right)^{\wedge} 3 / 3 / G 14 / 1000 / H 14$ & $=E 14^{*} D 14^{\wedge} 4 / 8 / G 14 / 1000 / H 14^{*} 12^{\wedge} 3$ & $=K 14+L 14$ \\
\hline 15 & 3 & $W 27 \times 84$ & 14 & 2 & 50 & 29 & 2850 & $=F 15^{*}\left(D 15^{\star} 12\right)^{\wedge} 3 / 3 / G 15 / 1000 / H 15$ & $=E 15^{\star} D 15^{\wedge} 4 / 8 / G 15 / 1000 / H 15^{\star} 12^{\wedge} 3$ & $=K 15+L 15$ \\
\hline 16 & 4 & $W 21 \times 62$ & 15 & 3 & 10 & 29 & 1330 & $=F 16^{*}\left(D 16^{*} 12\right)^{\wedge} 3 / 3 / G 16 / 1000 / H 16$ & $=E 16^{\star} D 16^{\wedge} 4 / 8 / G 16 / 1000 / H 16^{\star} 12^{\wedge} 3$ & $=K 16+L 16$ \\
\hline 17 & 5 & $W 18 \times 76$ & 12 & 2.5 & 30 & 29 & 1330 & $=F 17^{\star}\left(D 17^{*} 12\right)^{\wedge} 3 / 3 / G 17 / 1000 / H 17$ & $=E 17^{\star} D 17^{\wedge} 4 / 8 / G 17 / 1000 / H 17^{\star} 12^{\wedge} 3$ & $=K 17+L 17$ \\
\hline 18 & 6 & $W 24 \times 62$ & 15 & 3 & 20 & 29 & 1550 & $=F 18^{*}\left(D 18^{*} 12\right)^{\wedge} 3 / 3 / G 18 / 1000 / H 18$ & $=E 18^{*} D 18^{\wedge} 4 / 8 / G 18 / 1000 / H 18^{*} 12^{\wedge} 3$ & $=K 18+L 18$ \\
\hline 19 & 7 & $W 21 \times 83$ & 14 & 3 & 24 & 29 & 1830 & $=F 19^{*}\left(D 19^{*} 12\right)^{\wedge} 3 / 3 / G 19 / 1000 / H 19$ & $=E 19^{*} D 19^{\wedge} 4 / 8 / G 19 / 1000 / H 19^{*} 12^{\wedge} 3$ & $=K 19+L 19$ \\
\hline 20 & 8 & $W 21 \times 50$ & 12 & 3 & 20 & 30 & 984 & $=F 20^{*}\left(D 20^{*} 12\right)^{\wedge} 3 / 3 / G 20 / 1000 / H 20$ & $=E 20^{\star} D 20^{\wedge} 4 / 8 / G 20 / 1000 / H 20^{*} 12^{\wedge} 3$ & $=K 20+L 20$ \\
\hline 21 & 9 & $W 24 \times 76$ & 14 & 4 & 30 & 30 & 2100 & $=F 21^{*}\left(D 21^{*} 12\right)^{\wedge} 3 / 3 / G 21 / 1000 / H 21$ & $=E 21^{\star} D 21^{\wedge} 4 / 8 / G 21 / 1000 / H 21^{*} 12^{\wedge} 3$ & $=K 21+L 21$ \\
\hline 22 & 10 & $W 27 \times 94$ & 15 & 4 & 35 & 30 & 3270 & $=F 22^{*}\left(D 22^{*} 12\right)^{\wedge} 3 / 3 / G 22 / 1000 / H 22$ & $=E 22^{*} D 22^{\wedge} 4 / 8 / G 22 / 1000 / H 22^{*} 12^{\wedge} 3$ & $=K 22+L 22$ \\
\hline 23 & 11 & $W 21 \times 68$ & 13 & 3 & 24 & 29 & 1480 & $=F 23^{*}\left(D 23^{*} 12\right)^{\wedge} 3 / 3 / G 23 / 1000 / H 23$ & $=E 23^{*} D 23^{\wedge} 4 / 8 / G 23 / 1000 / H 23^{*} 12^{\wedge} 3$ & $=K 23+L 23$ \\
\hline 24 & 12 & $W 24 \times 94$ & 16 & 3.5 & 18 & 29 & 2700 & $=F 24^{*}\left(D 24^{*} 12\right)^{\wedge} 3 / 3 / G 24 / 1000 / \mathrm{H} 24$ & $=E 24^{\star} D 24^{\wedge} 4 / 8 / G 24 / 1000 / H 24^{*} 12^{\wedge} 3$ & $=K 24+L 24$ \\
\hline 25 & 13 & $W 18 \times 86$ & 13 & 3 & 25 & 29 & 1530 & $=F 25^{\star}\left(D 25^{*} 12\right)^{\wedge} 3 / 3 / G 25 / 1000 / H 25$ & $=E 25^{\star} D 25^{\wedge} 4 / 8 / G 25 / 1000 / H 25^{\star} 12^{\wedge} 3$ & $=K 25+L 25$ \\
\hline 26 & 14 & $W 21 \times 73$ & 14 & 3.5 & 35 & 30 & 1600 & $=F 26^{*}\left(D 26^{*} 12\right)^{\wedge} 3 / 3 / G 26 / 1000 / H 26$ & $=E 26^{\star} D 26^{\wedge} 4 / 8 / G 26 / 1000 / H 26^{*} 12^{\wedge} 3$ & $=K 26+L 26$ \\
\hline 27 & 15 & $W 18 \times 65$ & 12 & 2.5 & 20 & 29 & 1070 & $=F 27^{*}\left(D 27^{*} 12\right)^{\wedge} 3 / 3 / G 27 / 1000 / H 27$ & $=E 27^{\star} D 27^{\wedge} 4 / 8 / G 27 / 1000 / H 27^{\star} 12^{\wedge} 3$ & $=K 27+L 27$ \\
\hline 28 & 16 & $W 24 \times 84$ & 16 & 2.8 & 24 & 29 & 2370 & $=F 28^{*}\left(D 28^{*} 12\right)^{\wedge} 3 / 3 / G 28 / 1000 / H 28$ & $=E 28^{*} D 28^{\wedge} 4 / 8 / G 28 / 1000 / H 28^{*} 12^{\wedge} 3$ & $=K 28+L 28$ \\
\hline 29 & 17 & $W 21 \times 93$ & 14 & 4 & 30 & 29 & 2070 & $=F 29^{*}\left(D 29^{*} 12\right)^{\wedge} 3 / 3 / G 29 / 1000 / H 29$ & $=E 29^{*} D 29^{\wedge} 4 / 8 / G 29 / 1000 / H 29^{*} 12^{\wedge} 3$ & $=K 29+L 29$ \\
\hline 34 & 18 & $W 18 \times 50$ & 12 & 2.6 & 18 & 30 & 800 & $=F 34^{*}\left(D 34^{*} 12\right)^{\wedge} 3 / 3 / G 34 / 1000 / H 34$ & $=E 34^{*} D 34^{\wedge} 4 / 8 / G 34 / 1000 / H 34^{*} 12^{\wedge} 3$ & $=K 34+L 34$ \\
\hline
\end{tabular}

Table 3 
Here the following formula was used to find the maximum deflection at the free end of the cantilever beam:

$$
\delta_{\max }=\frac{w L^{4}}{8 E I}+\frac{M L^{2}}{2 E I}
$$

\section{Sample Problem 2 (with Answers):}

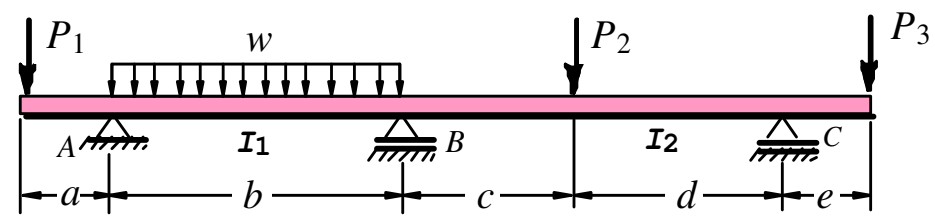

A continuous beam is given as shown. Using the Three-Moment Equation, determine:

(a) the bending moment at support $B$.

(b) the support reaction at $A$

(c) the support reaction at $B$

(d) the support reaction at $C$

\section{Solution:}

The students are assigned the problems as numbered in column 1. The known parameters for each student's problem are given in columns 2 through 12. The answers for each problem are in the 4 last columns, these columns are not on the assignment sheet for the students

\begin{tabular}{|c|c|c|c|c|c|c|c|c|c|c|c|c|c|c|c|}
\hline & $\boldsymbol{a}$ & $\boldsymbol{b}$ & $\boldsymbol{c}$ & $\boldsymbol{d}$ & $\boldsymbol{e}$ & $\boldsymbol{I}_{1}$ & $\boldsymbol{I}_{2}$ & $\boldsymbol{w}$ & $\boldsymbol{P}_{1}$ & $\boldsymbol{P}_{2}$ & $\boldsymbol{P}_{3}$ & $\boldsymbol{M}_{\mathrm{B}}$ & $\boldsymbol{A}_{\mathrm{y}}$ & $\boldsymbol{B}_{\mathrm{y}}$ & $\boldsymbol{C}_{\mathrm{y}}$ \\
\hline & $\mathrm{ft}$ & $\mathrm{ft}$ & $\mathrm{ft}$ & $\mathrm{ft}$ & $\mathrm{ft}$ & & & $\mathrm{k} / \mathrm{ft}$ & $\mathrm{kip}$ & $\mathrm{kip}$ & $\mathrm{kip}$ & $\mathrm{k}-\mathrm{ft}$ & $\mathrm{kip}$ & $\mathrm{kip}$ & $\mathrm{kip}$ \\
\hline $\mathbf{1}$ & 2 & 6 & 3 & 3 & 2 & 2 & 1.5 & 20 & 10 & 80 & 20 & -74.29 & 60.95 & 114.76 & 54.29 \\
\hline 2 & 2 & 6 & 3 & 3 & 2 & 2 & 1.5 & 15 & 8 & 60 & 16 & -54.93 & 46.51 & 85.31 & 42.18 \\
\hline 3 & 2 & 6 & 3 & 3 & 2 & 2 & 1.5 & 10 & 5 & 42 & 11 & -37.86 & 30.36 & 58.29 & 29.36 \\
\hline 4 & 2 & 6 & 3 & 3 & 2 & 2 & 1.5 & 12 & 6 & 45 & 12 & -42.64 & 36.89 & 66.71 & 31.39 \\
\hline 12 & 2 & 6 & 3 & 3 & 2 & 2 & 1.5 & 6 & 4 & 24 & 8 & -20.71 & 19.88 & 32.90 & 19.21 \\
\hline
\end{tabular}

Table 4 
The following is an example of a quiz which has been created for an individual student. Each student in the class gets a different personalized problem. The instructor has a master spread sheet with the answers for each individualized quiz.

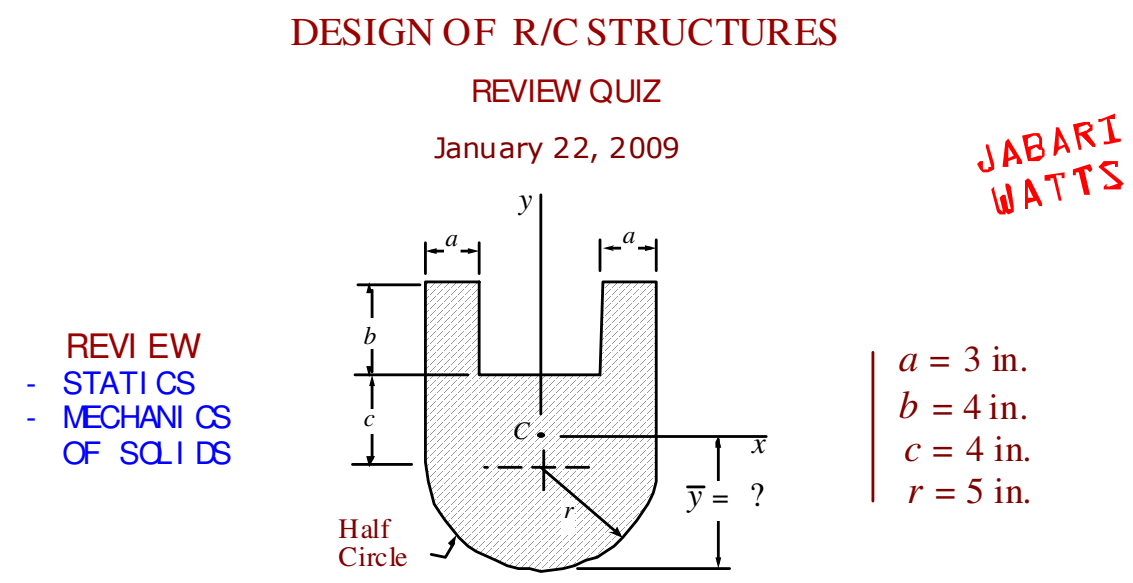

Solution:

A composite area is given as shown. Determine the following:
(a) the centroid of the shaded area $(\bar{y}=$ ?)
(b) the moment of inertia about the horiz. centroidal axis
(c) the moment of inertia about the vert. centroidal axis
$\bar{y}=?$
$I_{c x}=$ ?
$I_{c y}=$ ?

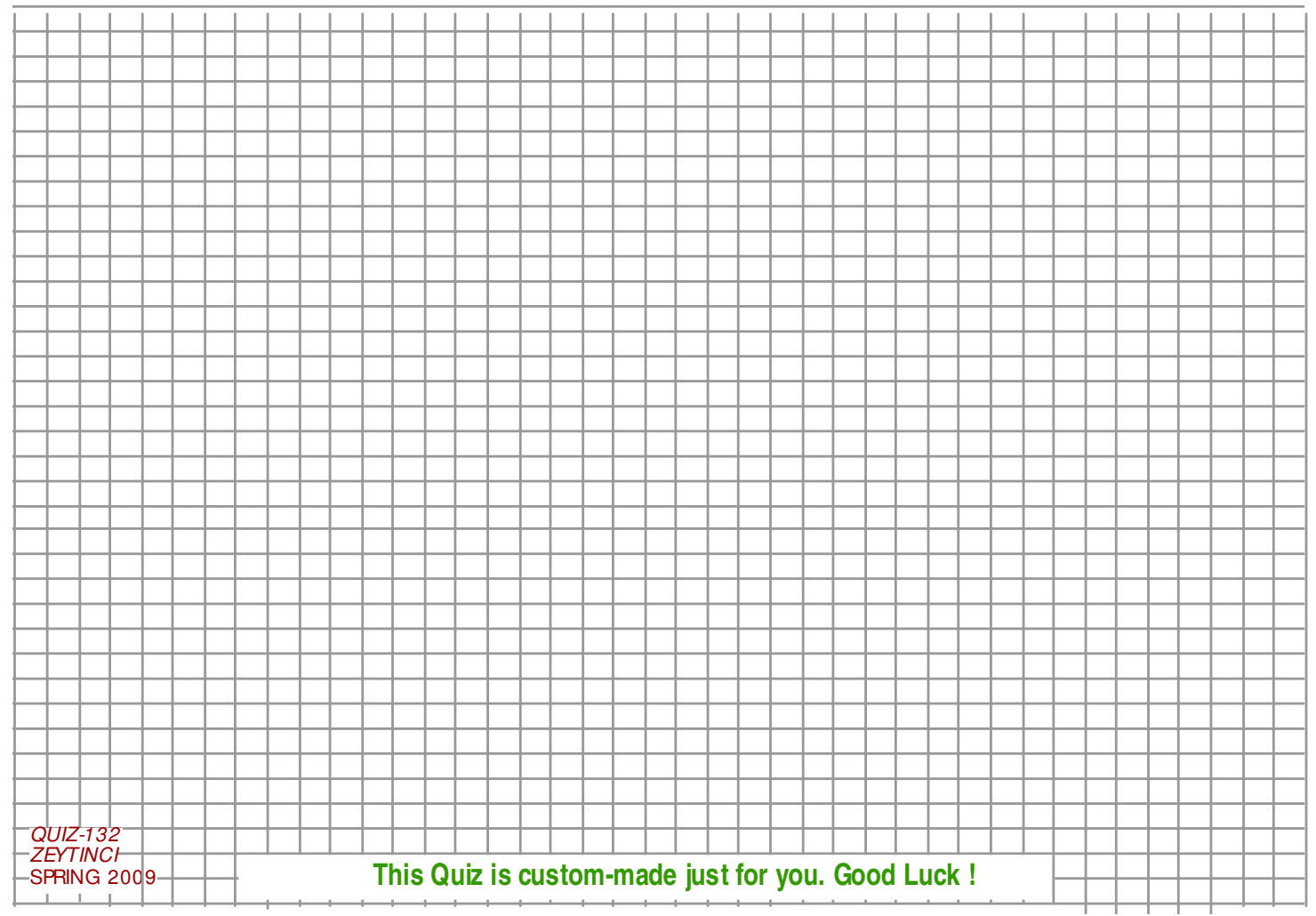

Table 5 


\section{Answer Sheet: Centroid and Moments of Inertia}

The following is a copy of the Excel spreadsheet with the answers for the centroid problem.

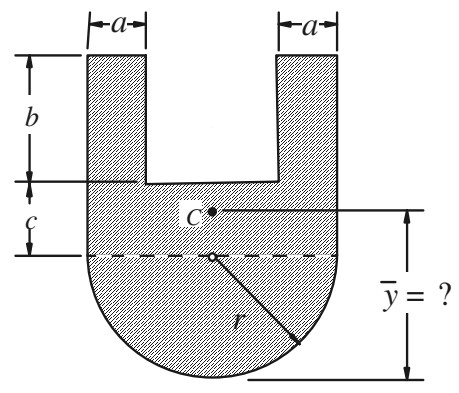

\begin{tabular}{|c|c|c|c|c|}
\hline & $a$ & $b$ & $c$ & $r$ \\
\hline 1 & in. & in. & in. & in. \\
\hline 2 & 2.5 & 3.0 & 4.0 & 5.0 \\
\hline 3 & 3.0 & 4.0 & 6.0 & 5.0 \\
\hline 11 & 2.0 & 3.0 & 2.0 & 4.0 \\
\hline
\end{tabular}

\begin{tabular}{|c|c|c|}
\hline$\nabla$ & $I_{\mathrm{cx}}$ & $I_{\mathrm{cy}}$ \\
\hline in. & $\mathrm{in}^{4}$ & $\mathrm{in}^{4}$ \\
\hline 5.55 & 628.90 & 396.53 \\
\hline 5.84 & 857.29 & 797.52 \\
\hline 7.34 & 1857.45 & 1057.44 \\
\hline 4.29 & 273.44 & 297.86 \\
\hline
\end{tabular}

Table 6

\section{Statistical Analysis}

To establish a quantitative relationship between the performance of students in the traditionally taught class (before) and the individually assigned problem work class (after), the Effectiveness Index (EI) was used as an indicator of improved performance. To accomplish this, the mean values for the CIs (the EI) before and after were analyzed to see if there was a significant difference in the values $\triangle$. See Figure 1 . Due to the relatively small size of the classes 12 students in the before class and 13 students in the after class, the $t$ test was used for the determination of significance in the mean values for the before and after courses. Because the students, while different individuals, were all typical of the student body enrolling in the civil engineering program at the university, we assumed they would be representative of the same population of students. To validate this assumption, that of homogeneity of the standard 
deviations of the before and after classes, the $F$ test was applied to the variances of the two samples. The calculated $F$ statistic equals the ratio of the square of the variance after with that of the square of the variance before. For our example this value came out to be 3.000. The tabulated $F$ value for a $1 \%$ level of significance for the degrees of freedom (12/11) equals 4.4000 (table 10 reference). Therefore the samples are satisfactory for a comparison of their mean values using the $t$ test. (See table 7.)

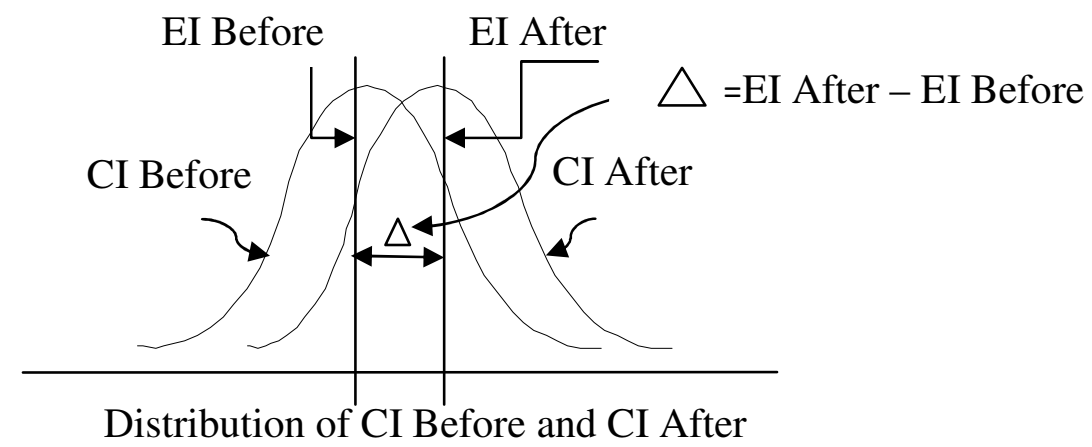

Figure 1

\begin{tabular}{|c|c|c|c|c|c|c|c|}
\hline & Cl-Before & & & & Cl After & & \\
\hline & $n=12$ & & $\left(x-x_{\mathrm{mB}}\right)^{2}$ & & $n=13$ & & $\left(x-x_{\mathrm{mA}}\right)^{2}$ \\
\hline & & & & & 1185 & & (20070 \\
\hline & 0.752 & & 0.04544 & & $\begin{array}{l}1.185 \\
0.706\end{array}$ & & 0.00078 \\
\hline & 1.082 & & 0.01365 & & $\begin{array}{l}0.196 \\
0.784\end{array}$ & & 0.73032 \\
\hline & 0.389 & & $\begin{array}{l}0.001<4 \\
0.33197\end{array}$ & & 0.760 & & 0.15761 \\
\hline & 1.168 & & 0.04114 & & 1.119 & & 0.00144 \\
\hline & 1.263 & & 0.08870 & & 1.228 & & 0.00504 \\
\hline & 0.861 & & 0.01085 & & 1.826 & & 0.44756 \\
\hline & 0.463 & & 0.25217 & & 2.000 & & 0.71065 \\
\hline & 1.478 & & 0.26299 & & 2.000 & & 0.71065 \\
\hline & 1.000 & & 0.00121 & & 1.104 & & 0.00281 \\
\hline & 1.158 & & 0.03718 & & 1.176 & & 0.00036 \\
\hline & 1.038 & & 0.00530 & & 0.039 & & 1.24992 \\
\hline & & & & & 1.024 & & 0.01769 \\
\hline$\Sigma X_{\mathrm{B}}=$ & 11.582 & $\sum\left(\mathrm{x}-\mathrm{x}_{\mathrm{mB}}\right)^{2}=$ & 1.09186 & $\Sigma X_{A}=$ & 15.041 & $\sum\left(x-x_{\mathrm{mA}}\right)^{2}=$ & 3.57397 \\
\hline$X_{\mathrm{mB}}=$ & 0.9652 & $\mathrm{Sd}_{\mathrm{B}}=$ & 0.31506 & $\mathrm{X}_{\mathrm{mA}}=$ & 1.157 & $S \mathrm{~d}_{\mathrm{A}}=$ & 0.54574 \\
\hline & & $\mathrm{S}_{\mathrm{dma}}=$ & 0.09095 & & & $S_{\mathrm{dmb}}=$ & 0.15136 \\
\hline & $F=$ & $\mathrm{Sd}_{\mathrm{a}}^{2} / \mathrm{S} d_{\mathrm{b}}^{2}=$ & 3.00050 & & & & \\
\hline & $F_{12 / 11}=$ & & 4.40000 & & & & \\
\hline & & & & & & & \\
\hline
\end{tabular}




\begin{tabular}{|l|c|c|c|c|c|}
\hline & $E \mathrm{I}_{\mathrm{A}}-E \mathrm{I}_{\mathrm{B}}=$ & 0.19183 & $t=1.08636$ & & \\
\hline & \multicolumn{3}{|c|}{$\begin{array}{c}\text { For 23 degrees of freedom a } t \text { value of } 1.09 \text { represents } 85.6 \% \\
\text { confidence that the mean values are different, or a } 14.4 \% \\
\text { likelihood that the difference is due to chance. }\end{array}$} & \\
\hline
\end{tabular}

\section{Table 7}

In summary, the performance of students in a class taught by the instructor using traditional assignments was measured by calculating the $\mathrm{CI}$ for each student and expressing the class performance with the average of all CI's, the EI. This same analysis was made for a class taught by the instructor using the individual assignment method. With the homogeneity established the $t$ distribution was used to compare the values of the Efficiency Index before and after. This analysis resulted in a confidence level of $87.5 \%$ that the difference was due to the instructional strategy of individualized assignments, or a $12.5 \%$ likelihood that the difference in the EI values was due to chance.

\section{Student Anecdotal Comments}

While not quantifiable, student comments were insightful when considering ancillary benefits of individual problem assignments for teaching problem-oriented courses. The following represents a collective impression of a range of student comments over a period of years that the authors have used this technique. "The course is like a custom made suit; I felt special working on my own problems." Students who thought they could fly through the course with little effort quickly discovered this would not be possible and usually dropped the course. Average students who depended on copying assignments when they ran out of time said, "This course was good and bad: it made me knuckle down and do the work." A number of students remarked, "The individualized assignments encouraged true collaborative work. You could not just copy one another's solution, we had to work as a team and understand the solutions in order to complete our own individual problems." "The individualized problems necessitated that we spend more time on the course, resulting in a better understanding of the subject matter." "We are so lucky and privileged to have instructors that utilize such creative and innovative teaching methods."

\section{Conclusion}

The application of the individualized assignments for students in engineering courses at UDC is a work in progress. For this paper the application of the method for a single course was presented. This method has been implemented in a number of courses and can be used in any course where formulas and relationships are used. We have not collected sufficient data for analysis of other courses. The authors are in process of assembling data from other courses that have been taught by the same instructor by both traditional assignments and individualized assignments. When this work is completed the results will be shared with the ASEE community. The development of the $\mathrm{CI}$ and EI has given us great hope that this innovative method of measuring capability and effectiveness may prove applicable in many other academic situations.

\section{Acknowledgement}


The authors wish to acknowledge the assistance of Professor William Rice of the UDC math department.

\section{References}

Basic Statistical Methods for Engineers and Scientist, by Neville and Kennedy, International Textbook Co., 1964 